\title{
Aortostial in-stent restenosis three months after primary percutaneous coronary intervention of the right coronary ostium in a patient presenting with cardiogenic shock
}

\author{
Irzal Hadžlbegović*, Đeiti Prvulović, Božo Vujeva, Krešimir Gabaldo
}

General Hospital "Dr J. Benčević", Slavonski Brod, Croatia

Aortoostial lesions count for up to $3 \%$ of all pathologic findings on coronary angiography. Aortoostial stenting differs slightly from other anatomic sites, mostly because of the need for complete ostium coverage. Also, coronary ostia differ anatomically from other sites and are more prone to dissection. Aortoostial in-stent restenosis is even more challenging because of the protruding and often deformed struts. Aortoostial interventions during acute myocardial infarction are often complex and associated with hemodinamic instability. $^{1-3}$

We present a case of a 77 year old women who first presented with signs of acute inferior infarction with cardiogenic shock. Acute ostial occlusion of calcified right was found, together with significant LAD stenosis and subocclusion of a minor ACx. After numerous predilatations with non-compliant balloon bare metal stent was implanted in the RCA with good result. Patient recovered well, and was scheduled for myocardial ischemia assessment in 3 months. Two months after discharge postinfarction exertional angina occurred and she was readmitted for follow up coronary angiography.
Severe in-stent restenosis of the right coronary ostium was found. We present the technique for aortoostial right coronary artery in-stent restenosis used in this patient and discuss optimal revascularization strategies in acute coronary syndrome patients presenting with multivessel disease including aortoostial lesions.

KEYWORDS: ostial lesion, in-stent restenosis, multivessel disease, acute myocardial infarction.

\section{Received: $5^{\text {th }}$ Mar 2013}

*Address for correspondence: Andrije Štampara 42, HR-35000 Slavonski Brod, Croatia.

Phone: +385-35-201-201

E-mail: irzal@vip.hr

\section{Literature}

1. Dishmon DA, Elhaddi A, Packard K, Gupta V, Fischell TA. High incidence of inaccurate stent placement in coronary aortoostial disease. J Invasive Cardiol. 2011;23(8):322-6. 2. Al-Lamee R, lelasi A, Latib A, et al. Comparison of long-term clinical and angiographic outcomes following implantation of bare metal stents and drug-eluting stents in aorto-ostial lesions. Am J Cardiol. 2011;108(8):1055-60.

3. Burstein JM, Hong T, Cheema AN. Side-strut stenting technique for the treatment of aorto-ostial in-stent restenosis and deformed stent struts. J Invasive Cardiol. 2006;18(8):2347. 